\title{
Gas transportation system development in Mongolia under gas prices uncertainty
}

\author{
Darya Maksakova ${ }^{1 *}$ \\ ${ }^{1}$ Melentiev Energy Systems Institute SB RAS, Department of Complex and Regional Problems in Energy, Irkutsk, Russia
}

\begin{abstract}
The paper analyses the stability of a solution to a problem of gas transportation system development in terms of gas import prices. The object of the study is a future gas transportation system in Mongolia. The employed tools are based on an original optimization problem, which is aimed to support decision-making process when choosing capacity, location, and time for investments in gas infrastructure. Different scenarios of gas import prices are considered for Mongolia. A stable solution is defined as the solution that is included in the optimal plans for every scenario. A multi-criteria approach is proposed to expanding the area of stable solutions. In conclusion, the priority areas of gas transportation system development in Mongolia are highlighted.
\end{abstract}

Keywords. Mongolia, gas transportation system, gas price uncertainty.

\section{Introduction}

The issue of introducing natural gas into Mongolia's energy mix has been discussed for a long time. The need in gas is primarily connected with ecological concerns and flexibility of Mongolia's power system. Given the absence of domestic conventional natural gas resources, in 2018 the country started to import liquefied natural gas (LNG) from China. In 2019 the first import supplies from Russia were received. The research aimed to identify the priority areas of gas infrastructure development in Northeast Asia has been conducted from the end of the last century [1]. A gas pipeline linking gas production centers in East Siberia with China and passing across Mongolia should have become a part of this infrastructure. At present, a feasibility study for such a pipeline is being conducted [2]. The implementation of this project will create the prerequisites to supply Mongolia's domestic consumers with gas, and this means that the creation of a national gas transportation system will be required.

\section{Model of gas transportation system creation and development}

Managing the process of gas transportation system development includes making the decisions on the stages of switching to gas from other fuels, structure and capacities of gas infrastructure, and import structure (the shares of LNG and pipeline gas in total import).

In order to support decision making in these areas, specific research tools are being developed. The core of these tools is a model of a national gas transportation system, described as a mixed integer linear problem.
The problem objective is to minimize a cumulative discounted cash outflow related to gas transportation system development and pipeline gas and LNG import.

Integer variables are the number of gas infrastructure facilities of a certain capacity. The facilities comprise liquefaction plants, regasification plants, gas pipelines and vehicles with cryogenic cisterns to deliver LNG. Table 1 shows the possible capacities of gas infrastructure facilities considered in the model.

Table 1. Infrastructure facilities capacity types.

\begin{tabular}{|c|c|c|}
\hline $\begin{array}{c}\text { Infrastructure } \\
\text { facility }\end{array}$ & Unit & $\begin{array}{c}\text { Capacity } \\
\text { types }\end{array}$ \\
\hline Pipelines & $\begin{array}{c}\text { billion cubic meters per } \\
\text { year }\end{array}$ & $\{0.4 ; 0.6 ; 1\}$ \\
\hline LNG vehicles & $\begin{array}{c}\text { cubic meters per } \\
\text { truck/cistern }\end{array}$ & $\{15 ; 40\}$ \\
\hline $\begin{array}{c}\text { Regasification } \\
\text { facilities }\end{array}$ & $\begin{array}{c}\text { million cubic meters } \\
\text { per year }\end{array}$ & $\{8 ; 17\}$ \\
\hline $\begin{array}{c}\text { Liquefaction } \\
\text { facilities }\end{array}$ & $\begin{array}{c}\text { million tons of LNG } \\
\text { per year }\end{array}$ & $\begin{array}{c}\{0.1 ; 0.5 ; 1.5 ; \\
2.5\}\end{array}$ \\
\hline
\end{tabular}

Spatially, the model aggregates gas demand in 25 nodes. Nodes are the centers of the biggest sums (administrative divisions) in Mongolia.

The modelling interval includes four five-year periods from 2021 to 2040 . The transit pipeline from Russia to China across Mongolia is assumed to be constructed in 2025. Thus, it is possible to import pipeline gas in the nodes located alongside the transit pipeline from this year.

National gas consumption in Mongolia is taken from the energy outlooks for Northeast Asia prepared by ESI SB RAS. Then national gas demand is disaggregated by

* Corresponding author: maksakova@isem.irk.ru 
nodes. In contrast to the traditional gas system models, for this model, gas demand is divided into pipeline gas demand and LNG demand. LNG demand is residential demand and demand from boilers located outside the centers of nodes as well as demand from transport, excluding public transport in Ulaanbaatar, where the usage of compressed natural gas is assumed.

Financial models of gas infrastructure facilities are developed to calculate cash outflows in the objective function.

These models estimate the following types of cash outflows:

-cash outflows related to constriction investments,

-cash outflows related to maintenance investments,

-cash outflows from operations.

Cash outflows related to construction investments occur before commissioning infrastructure facilities. It is assumed that the demand for gas will arise in some areas in 2025 and the pipeline from Russia to China across Mongolia will have been constructed by this year. Thus, some infrastructure facilities should be commissioned by this time and new facilities should be built during the following modelling periods to satisfy the growing demand. Construction investments consist in investments in capital equipment, auxiliary equipment, and buildings as well as design, engineering, and project management costs.

Maintenance investments take place when the useful life of assets is less than the length of the modelling interval (20 years from 2021 to 2040). In this case, new equipment should be commissioned in order to substitute the equipment that has been depreciated.

Cash outflows from operations consider personnel costs, maintenance services costs, consumables costs and taxes. They do not comprise the costs related to energy losses and own energy facilities' consumption because these costs are accounted for in the national gas supply infrastructure model. For simplicity, to describe tax environment, only two parameters are used instead of detailed representation of tax regimes: the Value added tax (VAT) rate and the Total tax and Contribution Rate published by World Bank Group and PwC [3].

\section{Stable solutions}

The LNG/pipeline gas price ratio is one of the key determinants of gas import structure and gas system design in Mongolia in the long term. Different price ratios can lead to quite different solutions to the problem of gas transportation system creation and development. Thus, the problem of finding stable solutions under gas price uncertainty arises.

In the context of this paper, a stable solution is the solution that is optimal under different gas prices scenarios. It is proposed to expand the area of stable solutions by a step-by-step introduction of additional criteria. In other words, the problem of stable solutions is connected with multi-criteria decision-making.

The traditional approach to consider multi-criteria problems of energy systems development is to transform a multi-criteria problem into a one-criterion problem by choosing a main criterion and describing the other criteria as constraints [4]. However, for some cases, it can be difficult to determine the boundaries of such constraints. Another widespread approach is summing criteria multiplied by their weight factors, which reflect the importance of criteria. The main difficulty when employing this approach is to quantify these weight factors. Game theory approaches assume finding equilibrium situations resulted from applying the strategies of involved actors. For instance, finding a Pareto equilibrium, or the situation when it is not possible to improve the value of any one criterion without worsening the value of at least one other criterion, is proposed in ref. $[5,6]$ to support decision making process in energy planning. As a rule, a set of Pareto-optimal solutions consists of several elements, and choosing between these elements requires further research. Hierarchical methods are based on criteria ranking and can be employed along with other approaches.

The methods of analysing solution stability described in this paper are based on a hierarchy of criteria. The choice of this approach is connected with the absence of necessity to quantify the importance of criteria. The proposed methodology consists of the following steps:

1) Various scenarios are considered. Scenarios differ by LNG import prices while import prices for pipeline gas are the same. The reason is that for an import-based gas supply system, the LNG/pipeline gas price ratio has a more significant effect on gas infrastructure design than price levels have. Scenario 30\% assumes that the prices on imported LNG are $30 \%$ higher than the prices on imported pipeline gas. Scenario 50\%, Scenario 100\%, Scenario $150 \%$, and Scenario $200 \%$ have the similar meaning.

2) Gas infrastructure facilities that are included in or excluded from the optimal plans of the gas transportation system development problem for every scenario are identified. These gas infrastructure facilities comprise an initial area of stable solutions (area of stable solutions 1). The other gas infrastructure facilities, which are included in the optimal plan for at least one scenario but not for all scenarios, comprise an area of possible solutions.

The further steps are aimed at expanding the area of stable solutions and narrowing the area of possible solutions.

3) The second criterion that forms a new objective function for the gas infrastructure development problem is introduced, with the additional constraints fixing area of stable solutions 1. As a result, a new optimization problem is formulated. For the new problem, similarly to the steps described above, the proposed scenarios of gas import prices are considered. A new area of stable solutions and a new area of possible solutions are formed. Gas infrastructure facilities that are included in or excluded from the optimal plans of the new gas transportation system development problem for all scenarios and the facilities from area of stable solutions 1 comprise area of stable solutions 2 .

The minimization of gas import costs is proposed as the second criterion, based on the assumption that gas importing countries are more interested in creating a 
value chain on their territory and increasing the value of their currencies than cutting gas infrastructure costs.

4) Further, when it is necessary, the next criteria is taken and the first two steps are repeated. As a result, area of stable solutions 3 based on the third criteria is formed.

The third criterion proposed is energy efficiency maximization. For Mongolia, assuming that only import supplies would be used to satisfy demand, this criterion can be formulated as a ratio of gas consumption to gas import. Thus, area of stable solutions 3 would include the facilities that are not involved in the optimal plans of the previous problems for all scenarios, but ensure energy loss minimization for all scenarios, provided that the facilities from area of stable solutions 2 are constructed.

5) The area of stable solutions can be expanded further until equal solutions for every scenario are received or until the size of the area fits for decision making.

Fig. 1 demonstrates the described algorithm.

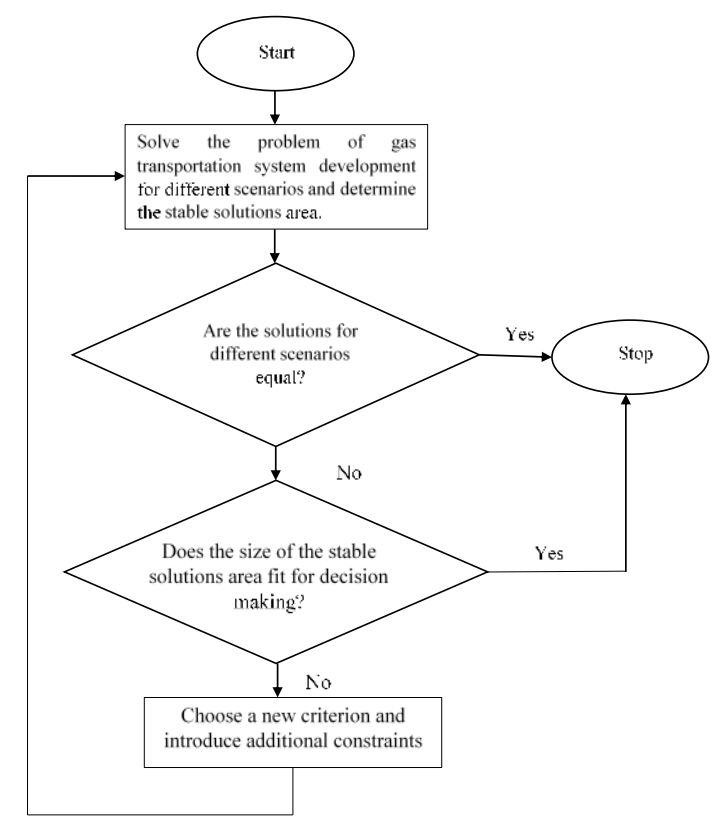

Fig. 1. Calculation algorithm for analyzing the stability of the solution to the problem of gas transportation system development.

\section{Preliminary results}

This section describes the results of the first step of the proposed methodology. These preliminary results are based on the solutions of the gas transportation system development problem aimed at cash costs minimization for the gas import prices scenarios described above.

The area of stable solutions for the initial problem of gas transportation system development does not include gas infrastructure facilities the number of which differs depending on the scenarios.
As a result of comparative analysis of the solutions for every scenario, the number of possible pipelines has been decreased significantly (Table 2).

Table 2. Area of stable solutions for gas pipelines.

\begin{tabular}{|c|c|c|c|c|}
\hline \multirow{2}{*}{ Index } & \multicolumn{4}{|c|}{$\begin{array}{c}\text { Commisioning } \\
\text { period }\end{array}$} \\
\cline { 2 - 5 } & $\mathbf{1}$ & $\mathbf{2}$ & $\mathbf{3}$ & $\mathbf{4}$ \\
\hline $\begin{array}{c}\text { The number of gas pipeline routes } \\
\text { from area of stable solutions 1, } \\
\text { which are not included in the } \\
\text { optimal plans for every scenario, } \\
\text { units }\end{array}$ & 94 & 93 & 91 & 96 \\
\hline $\begin{array}{c}\text { The number of possible gas } \\
\text { pipeline routes for every capacity } \\
\text { type, units }\end{array}$ & 96 & 96 & 96 & 96 \\
\hline
\end{tabular}

In terms of system efficiency, there are several routs (up to 5 depending on the modelling period) where gas pipelines could be constructed (Table 3 ). It is important that only pipelines with a capacity of 400 million cubic meters per year are constructed in every scenario. Thus, further analysis should be focused only on these five possible gas pipelines.

Possible pipeline routes (Table 3 ) lie either on the plains in the eastern part of the country, where construction costs are lower, or between large cities, characterized by relatively high gas demand.

Table 3. Possible gas pipelines.

\begin{tabular}{|c|c|}
\hline Route & Length, km \\
\hline Erdenet - Darkhan & 182 \\
\hline Darkhan - Sukhbaatar & 98 \\
\hline Darkhan - Zuunkharaa & 101 \\
\hline Sainshand - Baruun-Urt & 333 \\
\hline Baruun-Urt - Choibalsan & 193 \\
\hline
\end{tabular}

LNG import price rise is a driver of constructing additional liquefaction facilities. For the every scenario that builds liquefaction plants, only liquefaction plants with a capacity of 100 million tons of LNG per year are constructed. For some cases, several liquefaction plants of this capacity are constructed in the same node in different modelling periods. In other words, despite lowering unit construction and maintenance costs when a liquefaction capacity increases, small-scale LNG production becomes more efficient in terms of the time value of money and capacity factor.

The area of stable solutions for liquefaction plants (Table 4) is expanded significantly due to narrowing a set of possible capacities to one element, a capacity of 100 thousand tons of LNG per year, and a set of nodes, where liquefaction plants could be constructed, from 25 to 4-5 nodes depending on the period. 
Table 4. Area of stable solutions for liquefaction plants.

\begin{tabular}{|c|c|c|c|c|}
\hline \multirow{2}{*}{ Index } & \multicolumn{4}{|c|}{$\begin{array}{c}\text { Commissioning } \\
\text { period }\end{array}$} \\
\hline & 1 & 2 & 3 & 4 \\
\hline $\begin{array}{c}\text { The number of nodes from area of } \\
\text { stable solutions 1, where } \\
\text { liquefaction plants are not } \\
\text { constructed for every scenario, } \\
\text { units }\end{array}$ & 20 & 21 & 21 & 21 \\
\hline Total number of nodes, units & 25 & 25 & 25 & 25 \\
\hline
\end{tabular}

Analysing the solutions to the gas transportation system development problem for different scenarios allowed decreasing the number of possible routes for LNG transportation. As Table 5 shows, for LNG vehicles with a capacity of 15 cubic meters, there is only one possible route in the first, third, and forth periods. For the second period, there are two possible routes. For LNG vehicles with a capacity of 40 cubic meters, there are twenty six possible routes in the first and forth periods, thirty two possible routes in the second period, and thirty nine possible routes in the third period. Commissioning period and route are the same in all scenarios for ninety one LNG vehicles.

Table 5. Area of stable solutions for LNG vehicles.

\begin{tabular}{|c|c|c|c|c|}
\hline & \multicolumn{3}{|c|}{ Commissioning period } \\
\cline { 2 - 5 } Index & $\mathbf{1}$ & $\mathbf{2}$ & $\mathbf{3}$ & $\mathbf{4}$ \\
\hline $\begin{array}{c}\text { The number of LNG } \\
\text { vehicles from area of stable } \\
\text { solutions 1, which are } \\
\text { included in the optimal } \\
\text { plans for every scenario ( } \\
\text { with a capacity of 40 cubic } \\
\text { meters), units }\end{array}$ & 10 & 6 & 29 & 46 \\
\hline $\begin{array}{c}\text { The number of LNG } \\
\text { transportation routes from } \\
\text { area of stable solutions 1, } \\
\text { which are not included in } \\
\text { the optimal plans for every } \\
\text { scenario, units }\end{array}$ & & & & \\
$\begin{array}{c}40 \text { cubic meters } \\
\text { 15 cubic meters }\end{array}$ & 70 & 64 & 57 & 70 \\
$\begin{array}{c}\text { Total } \\
\text { The number of possible } \\
\text { for every capacity type, } \\
\text { units }\end{array}$ & 96 & 96 & 96 & 96 \\
\hline
\end{tabular}

In nodes that are not supplied with pipeline gas, the construction of regasification facilities is required. The volumes of regasification capacities are determined by the structure and volumes of gas demand, stages of introducing natural gas into Mongolia's energy mix, and mode of gas transportation.
Table 6 demonstrates the area of stable solutions for regasification plants. In most cases, regasification plants with a capacity of 17 million cubic meters are constructed. Regasification plants with a capacity of 8 million cubic meters could be constructed only in one node in the first and second periods and in four nodes in the fourth period. Four regasification plants with a capacity of 8 million cubic meters are constructed in the fourth period in every scenario. Twenty eight regasification plants with a capacity of 17 million cubic meters are constructed during the modelling interval in every scenario.

Table 6. Area of stable solutions for regasification plants.

\begin{tabular}{|c|c|c|c|c|}
\hline \multirow{2}{*}{ Index } & \multicolumn{4}{|c|}{$\begin{array}{c}\text { Commissioning } \\
\text { period }\end{array}$} \\
\hline & 1 & 2 & 3 & 4 \\
\hline $\begin{array}{l}\text { The number of regasification } \\
\text { plants from area of stable } \\
\text { solutions } 1 \text {, which are included } \\
\text { in the optimal plans for every } \\
\text { scenario, units. }\end{array}$ & & & & \\
\hline 8 million cubic meters & - & - & - & 4 \\
\hline 17 million cubic meters & 4 & 5 & 11 & 8 \\
\hline $\begin{array}{l}\text { The number of nodes from area } \\
\text { of stable solutions } 1 \text {, which are } \\
\text { not included in the optimal } \\
\text { plans for every scenario, units }\end{array}$ & & & & \\
\hline 8 million cubic meters & 24 & 24 & 25 & 21 \\
\hline 17 million cubic meters & 20 & 19 & 17 & 16 \\
\hline Total number of nodes, units & 25 & 25 & 25 & 25 \\
\hline
\end{tabular}

As the preliminary results show, additional criteria could be introduce to expand the area of stable solutions and support decision making under the different gas prices scenarios. The calculations provided in this paper are finished with analising the initial problem. The implementation of further steps of the calculations algorithm on Figure 1 would allow receiving results that are more concrete.

\section{Conclusions}

The paper presents a methodological approach to estimating the stability of gas infrastructure development patterns for economies with a lack of conventional natural gas resources in terms of gas import prices uncertainty. The core of the developed research tools is a model of a national gas transportation system, described as a mixed integer linear problem.

Some preliminary results describing the stability of the solutions to the problem of Mongolia's gas transportation system creation and development have been obtained by employing the model. It is shown that the project of the gas pipeline from Russia to China 
passing across Mongolia is competitive and stable to changes in LNG import prices. Branches from the pipeline can be optimal for some routes in the eastern part of Mongolia and between several big gas consumption centers. In the western part of the country, gas supply should be based on LNG deliveries by road and rail transport. For some cities, which have access to pipeline gas, in terms of system efficiency and considering gas transportation costs and demand structure, it would be optimal to build small-scale LNG plants.

Further analysis of Mongolia's gas transportation system development trajectories based on the proposed approach assumes a step-by-step inclusion of additional criteria. This would provide a more holistic picture describing priority areas of gas infrastructure development and allow making conclusions on the scope of the approach, its opportunities and constraints.

The authors would like to thank AIMMS company for providing the software for academic purposes that allowed them to make the computations.

The research was carried out under the State Assignment Project (Topic No. FWEU-2021-0004, Registration No. AAAA-A21-121012090010-7) of the Fundamental Research Program of the Russian Federation for the period 2021-2025.

\section{References}

1. Northeast Asian Gas and Pipeline Forum (NAGPF), A Long-Term Vision of Natural Gas Infrastructure in Northeast Asia (2000)

URL : http://www.nagpf.info/research/1research.ht m (accessed June 5, 2021).

2. Feasibility analysis approved for Soyuz Vostok gas pipeline construction project (2021) URL: https://www.gazprom.com/press/news/2021/april/art icle526670/ (accessed June 18, 2021).

3. Paying taxes. Overall ranking and data tables (2020). URL:

https://www.pwc.com/gx/en/services/tax/publication s/paying-taxes-2020/overall-ranking-and-datatables.html (accessed June 18, 2021).

4. Y. Kononov, D. Kononov Izvestiia Rossiiskoi akademii nauk. Energetika 4, pp.21-30 (2018) DOI: 10.31857/S000233100002361-1

5. McCollum, D., V. Krey, K. Riahi, P. Kolp, M. Makowski and B. Schreck. The IIASA EnergyMulti Criteria Analysis Tool (ENE-MCA) (IIASA, Laxenburg, Austria, 2012)

6. P. Fragiacomo, G. Lucarelli, and G. Flori E3S Web of Conferences 238, $05002 \quad$ (2021) https://doi.org/10.1051/e3sconf/202123805002 